\title{
Hazard of cardiac catheterization in patients with ventricular pre-excitation
}

\author{
C. Ward, K. G. Lowe, and Hamish Watson \\ From the University Department of Cardiology, and the Royal Infirmary, Dundee
}

The scalar and intracardiac electrocardiograms recorded at the time of cardiac catheterization in 5 patients with ventricular pre-excitation have been analysed. Four patients had paroxysmal tachycardia on one or more occasions during the procedure. In each case where complete records were available the dysrhythmia was an atrial reciprocating tachycardia and this rhythm wasnoted at some time during each of the four procedures. Sinus rhythm could often be restored by stimulating the heart wall with the tip of the catheter.

Two out of three patients with no previous history of dysrhythmia developed tachycardia for the first time during cardiac catheterization.

Ventricular pre-excitation may be an innocent finding in patients with otherwise normal hearts. However, paroxysmal tachycardia occurs spontaneously in about 70 per cent of cases (Wolff, 1954; Chung, Walsh, and Massie, 1965) and the term Wolff-ParkinsonWhite syndrome (Wolff, Parkinson, and White, 1930) may then be used correctly. Paroxysmal tachycardia and an otherwise normal heart were essential features of the syndrome described by Wolff, Parkinson, and White, and the term should therefore not be used as an alternative name for ventricular pre-excitation when it is accompanied by neither of these features. The paroxysmal tachycardia when it occurs is usually a rapid, regular supraventricular tachycardia; much less frequently it is atrial flutter or fibrillation (Newman, Donoso, and Friedberg, 1966).

Although the majority of patients with ventricular pre-excitation have otherwise normal hearts, it has a well-recognized association with congenital heart disease, especially Ebstein's anomaly of the tricuspid valve, with cardiomyopathy, and with other cardiac disorders. Such patients may have to undergo diagnostic cardiac catheterization, and it may be anticipated that those with a history of paroxysmal tachycardia will develop a dysrhythmia during the procedure.

In those with ventricular pre-excitation and heart disease requiring cardiac catheterization, the opportunity may be taken to determine the mechanism of the dysrhythmia, to record

Received 23 August 197 I. the bundle of His electrocardiogram, and to study the spread of excitation in the ventricles (Watson and Lowe, 1967; Watson, EmslieSmith, and Lowe, 1967; Castillo and Castillanos, 1970).

We have catheterized 5 patients with ventricular pre-excitation and suspected congenital heart disease or cardiomyopathy (Table). Three had no history of paroxysmal tachycardia; of these, 2 had Ebstein's anomaly and the other a small ventricular septal defect. All 3 had type B (presumed right ventricular) pre-excitation. In the patient with a ventricular septal defect the procedure was uneventful and no tachycardia occurred. Paroxysmal tachycardia occurred during cardiac catheterization in both patients with Ebstein's anomaly. One (Case I) was catheterized in 1953 and 1959. On each occasion the procedure was abandoned because of prolonged supraventricular tachycardia unresponsive to carotid sinus pressure, but eventually settling spontaneously after several hours. At that time we were neither aware of the nature of the dysrhythmia nor of the method of terminating it. On the first occasion the onset of the dysrhythmia was not recorded, but on the second occasion it was. The dysrhythmia began immediately after the compensatory pause after a ventricular ectopic beat and was clearly a reciprocating atrial tachycardia. On the first occasion the catheter tip was in the right ventricle; on the second it was in the right atrium. The other patient (Case 2) developed tachycardia during angiocardiography. The dysrhythmia followed an atrial 
TABLE Cardiac catheterization in patients with ventricular pre-excitation

\begin{tabular}{|c|c|c|c|c|}
\hline $\begin{array}{l}\text { Case No. } \\
\text { and sex }\end{array}$ & $\begin{array}{l}\text { Age } \\
(y r)\end{array}$ & Scalar electrocardiogram & Clinical diagnosis & $\begin{array}{l}\text { Dysrhythmia during cardiac } \\
\text { catheterization }\end{array}$ \\
\hline $\mathbf{r}, \mathbf{M}$ & 12 & $\begin{array}{l}\text { Type B pre-excitation and } \\
\text { right bundle-branch block }\end{array}$ & Ebstein's anomaly & $\begin{array}{l}\text { Atrial reciprocating tachycardia } \\
\text { followed burst of ventricular } \\
\text { ectopic beats in RV; QRS } \\
\text { narrow }\end{array}$ \\
\hline 2, M & 12 & Type B pre-excitation & Ebstein's anomaly & $\begin{array}{l}\text { Atrial reciprocating tachycardia } \\
\text { followed atrial ectopic beat } \\
\text { during angiocardiography; } \\
\text { QRS narrow }\end{array}$ \\
\hline 3, M & 5 & Type B pre-excitation & $\begin{array}{l}\text { Small VSD (membranous } \\
\text { septum repaired) }\end{array}$ & No tachycardia \\
\hline $4, M$ & I8 dy & Type A pre-excitation & Paroxysmal tachycardia & $\begin{array}{l}\text { Atrial reciprocating tachycardia } \\
\text { provoked by atrial ectopic } \\
\text { beat followed by long PR } \\
\text { interval; ORS narrow }\end{array}$ \\
\hline $5, F$ & 24 & Type A pre-excitation & $\begin{array}{l}\text { Paroxysmal tachycardia, } \\
\text { cardiomyopathy }\end{array}$ & $\begin{array}{l}\text { Atrial reciprocating tachycardia, } \\
\text { recurrent paroxysms; QRS } \\
\text { narrow }\end{array}$ \\
\hline
\end{tabular}

ectopic beat and again was a reciprocating atrial tachycardia.

Two patients had type A (presumed left ventricular) pre-excitation; one (Case 5) had suspected cardiomyopathy having had an episode of unexplained left ventricular failure after a recent pregnancy and the other (Case 4) suspected congenital heart disease, not, however, confirmed at catheterization. Both had a history of spontaneous paroxysmal tachycardia. Case 4 developed reciprocating atrial tachycardia during cardiac catheterization, after atrial ectopic beats when the catheter tip was in the right atrium. Case 5 had recurrent attacks of reciprocating tachycardia during catheterization of both the right ventricle and the right atrium; on each occasion it was precipitated by atrial ectopic beats. In both patients the dysrhythmia was easily terminated by stimulating the atrial or ventricular endocardium with the catheter tip to produce ectopic beats.

\section{Mechanism of atrial tachycardia}

In each of our cases, as is usual, the QRS was narrowed during the tachycardia due to loss of the delta wave. In those paroxysms with complete records, initiation and termination - of tachycardia by atrial or ventricular ectopic beats were noted and a typical recording is shown in the Figure.

An atrial ectopic beat $(\mathrm{Pe})$ is recognized by its prematurity and by its aberrant form recorded from the electrode on the tip of the catheter. After a prolonged Pe-R interval the

- first QRS complex of the tachycardia is followed quickly by a $P$ wave showing reversed polarity $\left(\mathrm{P}^{\prime}\right)$ : the initial atrial activation of the dysrhythmia. Antegrade conduction solely by the AV node and bundle of His accounts for the narrow QRS with absence of the delta wave. This paroxysm was terminated during a burst of multifocal atrial ectopics as the catheter tip was pressed against the lateral wall of the right atrium.

\section{Discussion}

Incidence of dysrhythmia in pre-excitation during diagnostic cardiac catheterization Spontaneous dysrhythmia in preexcitation is most commonly said to be supraventricular tachycardia, less commonly atrial fibrillation and, least commonly, atrial flutter; the incidence being 80,16 , and 4 per cent, respectively (Newman et al., 1966). Sudden death is well known to occur in such patients. The mechanism of this is not clear, but it has been suggested that atrial fibrillation may lead to ventricular fibrillation: rapid, repeated stimulation of the ventricle, probably via the bypass fibres, resulting in occasional stimulation of the ventricle during the vulnerable period (Rosenbaum, 1970). However, ventricular pre-excitation has not been commented on as a particular hazard during cardiac catheterization and seems to be infrequently associated with serious dysrhythmia in diagnostic procedures. The Co-operative Study on Cardiac Catheterization of the American Heart Association (Braunwald and Swan, 1968) was a prospective study of 12,367 diagnostic catheterizations over a two-year period. In this series, 149 patients experienced 153 major dysrhythmias. Of 59 cases of ventricular fibrillation, 23 occurred during the 3,290 coronary arteriographies, 6 of them in patients without heart disease, one 

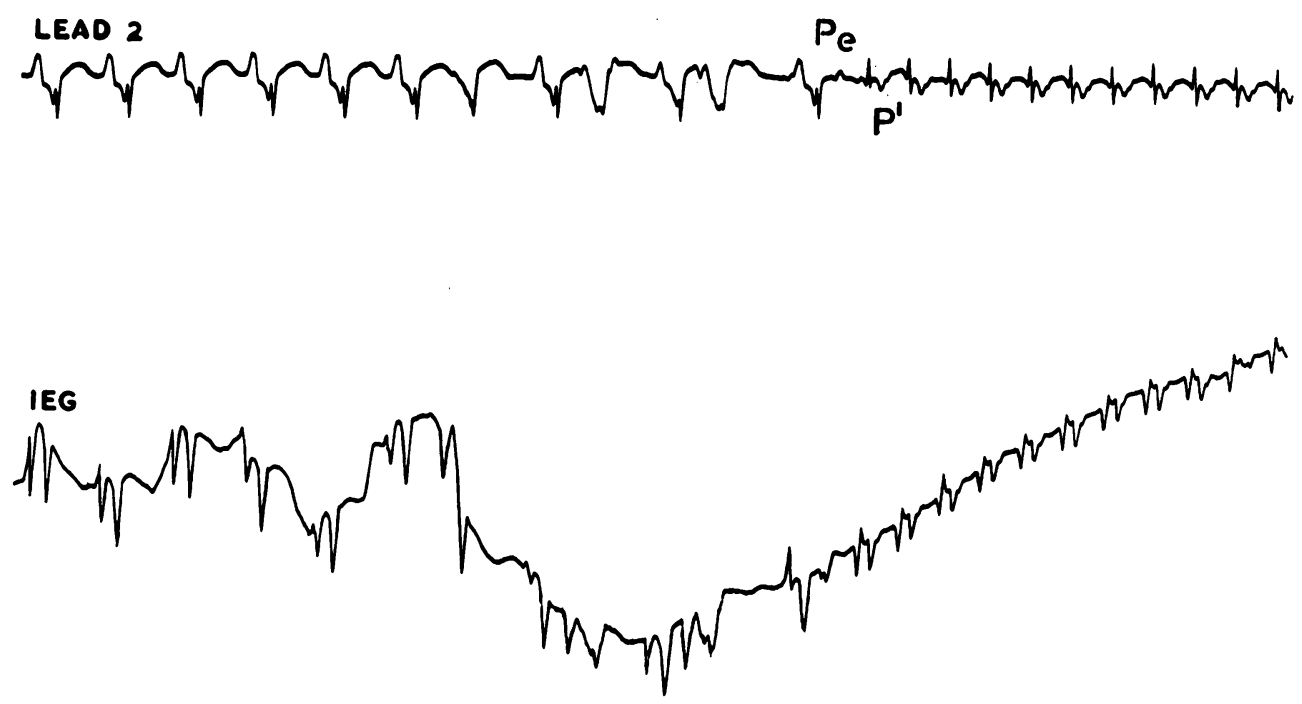

FIG. Lead II of the electrocardiogram and the intracardiac electrocardiogram (IEG) recorded from Case 4 during cardiac catheterization. Pe indicates atrial ectopic beat and $P^{\prime}$ indicates reciprocal atrial activation showing reversed polarity. For full description see text.

of whom had Wolff-Parkinson-White syndrome. Supraventricular tachydysrhythmias were surprisingly infrequent, possibly because minor episodes were disregarded for the purposes of the study. Of the 35 cases recorded in the whole series of 12,367 patients, 29 were in the age group 6 to 61 years. Three of these 29 patients had Wolff-Parkinson-White syndrome, I8 had congenital heart disease, and 5 of the 18 had Ebstein's anomaly. It is not reported whether any of the 3 cases of WolffParkinson-White syndrome had Ebstein's anomaly. Because Ebstein's anomaly is so commonly associated with ventricular preexcitation and also because catheterization has in the past been considered especially hazardous in patients with Ebstein's anomaly, it would be important to investigate this further. Fortunately one of us (H.W.) has some data on this point. In a study of 406 patients with Ebstein's anomaly of the tricuspid valve, 303 underwent cardiac catheterization. Of these 303 diagnostic catheterizations, 53 were said to be complicated by paroxysmal supraventricular tachycardia. Eleven of these 53 patients had ventricular pre-excitation and $I$ of them died from heart failure because the ventricular rate could not be controlled.

Four of our 5 patients with pre-excitation had paroxysmal tachycardia during cardiac catheterization. In the 2 with a history of spontaneous dysrhythmia, frequent episodes of tachycardia occurred during catheteriza- tion. Two of the other three developed tachycardia, one of them on two separate occasions.

Nature of reciprocal atrial tachycardia

Granted that a bypass mechanism accounts for ventricular pre-excitation, then a pathway exists for re-entry of the excitation wave into the atrium. Antegrade conduction from atrium to ventricle may be by the normal pathway (AV node and bundle of His) and re-entry by the bypass fibres or, less commonly, vice versa. Such a reciprocal rhythm, the so-called atrial or reversed reciprocating tachycardia, has been recognized infrequently in patients with pre-excitation from recordings of spontaneous episodes of tachycardia (Wolff, I954; Harnischfeger, 1959; Schamroth, 1960; Harris, Semler, and Griswold, 1964; Kistin, 1965; McHenry, Knoebel, and Fisch, I966; Roelandt and Van der Hauwaert, I968; Schamroth and Coskey, 1969; Liuria and Hale, 1970), though it may well be the usual mechanism of the paroxysmal tachycardia. Unequal responsiveness or refractoriness of two AV nodal pathways is essential, otherwise the potential initiating impulse would traverse both pathways simultaneously, and reciprocal activation of the atria would be impossible. The dysrhythmia is preceded by a prolonged PR interval, a prolonged $\mathbf{R P}^{\prime}$ interval, or both, producing a prolonged atrial reciprocal time. ( $\mathbf{P}^{\prime}$ indicates retrograde atrial activation.) Whichever of these factors is present (pro- 
longed $\mathbf{P R}$ or prolonged $\mathbf{R} \mathbf{P}^{\prime}$ ) the result is the same; the atrium is sufficiently recovered to respond to the reciprocal impulse. This applies whether the initiating impulse is of atrial,

- nodal, or ventricular origin. Thus the dysrhythmia can be precipitated by sinus beats or by ectopic beats of atrial, nodal (AV junctional), or ventricular origin (Schamroth and Yoshonis, 1969). These authors have suggested that dual pathways may exist within the AV node and function in some patients ? with ventricular pre-excitation, the narrowed QRS and loss of delta wave during paroxysmal tachycardia being explained by ventricular activation via the normal (non bypass) route. The mechanism of reciprocal rhythm in patients with ventricular pre-excitation was worked out by deductive reasoning, but recent

- experimental work involving atrial pacing (Durrer et al., 1967; Lau et al., 1967) and His bundle recording (Giraud et al., 1960; Watson et al., 1967; Scherlag et al., - 1969) has served to validate the work of earlier investigators. The pathway of the reciprocating tachycardia has been mapped by the use of His bundle recordings (Castillo and Castillanos, 1970; Massumi, 1970), and termination of reciprocating tachycardia by endocardial stimulation has been demonstrated (Massumi, Kistin, and Tawakkol, I967; Ryan et al., I968). Though critical tim-

- ing is apparently essential for termination of the dysrhythmia by a single induced ectopic > beat, repeated stimulation either of the atrium or the ventricle will often stop the paroxysm.

\section{Conclusions}

Our studies have shown that dysrhythmia is - common during cardiac catheterization in patients with ventricular pre-excitation. Using

- intracardiac electrocardiography and continuous tape recording throughout the proi cedure, the nature of the dysrhythmia can now be recognized. In those cases where the onset of the dysrhythmia was recorded, it was clear that the rhythm was a reciprocating atrial tachycardia. Sinus rhythm can often be restored by stimulating the wall of the atrium or the ventricle with the tip of the catheter to

$=$ induce ectopic beats. However, the dysrhythmia may be serious or even fatal.

Our findings add support to the suggestion that the usual mechanism of dysrhythmia in patients with ventricular pre-excitation is an atrial reciprocating tachycardia.

\section{References}

Braunwald, E., and Swan, H. J. C. (1968). Eds. Co-operative Study on Cardiac Catheterization. The American Heart Association, New York.
Castillo, C. A., and Castillanos, A. (1970). His bundle recordings in patients with reciprocating tachycardias and Wolff-Parkinson-White syndrome. Circulation, 42, 271.

Chung, K-Y., Walsh, T. J., and Massie, E. (1965). Wolff-Parkinson-White syndrome. American Heart fournal, 69, I16.

Durrer, D., Schoo, L., Schuilenburg, R. M., and Wellens, H. J. J. (1967). The role of premature beats in the initiation and the termination of supraventricular tachycardia in the Wolff-ParkinsonWhite syndrome. Circulation, 36, 644 .

Giraud, G., Peuch, P., Latour, H., and Hertault, J. (I960). Variations de potentiel liées à l'activité du système de conduction auriculo-ventriculaire chez l'homme (enregistrement électrocardiographiques endocavitaire). Archives des Maladies du Coeur et des Vaisseaux, 53, 757.

Harnischfeger, W. W. (1959). Hereditary occurrence of the pre-excitation (Wolff-Parkinson-White) syndrome with re-entry mechanism and concealed conduction. Circulation, 19, 28.

Harris, W. E., Semler, H. J., and Griswold, H. E. (I964). Reversed reciprocating paroxysmal tachycardia controlled by guanethidine in a case of Wolff-Parkinson-White syndrome. American Heart fournal, 67, 812.

Kistin, A. D. (1965). Atrial reciprocal rhythm. Circulation, 32, 687 .

Lau, S. H., Stein, E., Kosowsky, B. D., Haft, J. I., Lister, J. W., and Damato, A. N. (1967). Atrial pacing and atrioventricular conduction in anomalous atrioventricular excitation (Wolff-ParkinsonWhite syndrome). American fournal of Cardiology, 19, 354 .

Liuria, M. H., and Hale, C. G. (1970). Wolff-Parkinson-White syndrome in association with atrial reciprocal rhythm and reciprocating tachycardia. British Heart fournal, 32, 134.

Massumi, R. A. (1970). His bundle recordings in bilateral bundle-branch block combined with WolffParkinson-White syndrome. Antegrade type II (Mobitz) block and I:I retrograde conduction through the anomalous bundle. Circulation, 42, 287.

Massumi, R. A., Kistin, A. D., and Tawakkol, A. A. (1967). Termination of reciprocating tachycardia by atrial stimulation. Circulation, 36, 637.

McHenry, P. L., Knoebel, S. B., and Fisch, C. (1966). The Wolff-Parkinson-White (W-P-W) syndrome with supernormal conduction through the anomalous bypass. Circulation, 34, 734 .

Newman, B. J., Donoso, E., and Friedberg, C. K. (1966). Arrhythmias in the Wolff-Parkinson-White syndrome. Progress in Cardiovascular Diseases, 9, 147.

Roelandt, J., and Van der Hauwaert, L. G. (I968). Atrial reciprocal rhythm and reciprocating tachycardia in Wolff-Parkinson-White syndrome. Circulation, 38, 64 .

Rosenbaum, M. B. (1970). Panel discussion on WolffParkinson-White syndrome. In Symposium on Cardiac Arrhythmias. Ed. by E. Sandoe, E. FlenstedJensen, and K. H. Olesen. AB Astra, Södertälje, Sweden.

Ryan, G. F., Easley, R. M., Zaroff, L. I., and Goldstein, S. (1968). Paradoxical use of a demand pacemaker in treatment of supraventricular tachycardia due to the Wolff-Parkinson-White syndrome. Observation on termination of reciprocal rhythm. Circulation, 38, 1037.

Schamroth, L. (1960). Reversed reciprocating paroxysmal tachycardia and its relationship to the WolffParkinson-White syndrome. American Heart fournal, 59, 506. 
Schamroth, L., and Coskey, R. L. (1969). Reciprocal rhythm, the Wolff-Parkinson-White syndrome and unidirectional block. British Heart fournal, 31, 616.

Schamroth, L., and Yoshonis, K. F. (1969). Mechanisms in reciprocal rhythm. American fournal of Cardiology, 24, 224.

Scherlag, B. J., Lau, S. H., Helfant, R. H., Berkowitz, W. D., Stein, E., and Damato, A. N. (1969). Catheter technique for recorded His bundle activity in man. Circulation, 39, 13.

Watson, H., Emslie-Smith, D., and Lowe, K. G. (1967). The intracardiac electrocardiogram of human atrioventricular conducting tissue. American Heart Fournal, 74, 66.
Watson, H., and Lowe, K. G. (1967). Intracavity potentials in type B ventricular pre-excitation. British Heart fournal, 29, 505.

Wolff, L. (1954). Syndrome of short P-R interval with abnormal QRS complexes and paroxysmal tachycardia (W-P-W syndrome). Circulation, 10, 282.

Wolff, L., Parkinson, J., and White, P. D. (1930). Bundle-branch block with short P-R interval in healthy young people prone to paroxysmal tachycardia. American Heart fournal, 5, 685.

Requests for reprints to Dr. Hamish Watson, Department of Cardiology, The University, Dundee, DDI $4 \mathrm{HN}$.

\section{Corrigendum}

Parsons, C. G., Astley, R., Burrows, F. G. O., and Singh, S. P. (I97I). Transposition of great arteries. A study of 65 infants followed for I to 4 years after balloon septostomy. British Heart fournal, 33, 725-73I.

I regret that our summary of the paper by Venables (1970) was incorrect. The relevant passage in the Discussion, p. 729 , should read as follows.

Venables (1970) describes his experiences with 26 infants in a little less than 3 years. At the end of this study, 17 children survived. Of 7 early deaths, one appeared due to inadequate mixing of blood through the atrial septal defect. Four atrial perforations were noted. One perforation was discovered at postmortem examination in a baby who was moribund from diffuse pulmonary haemorrhage when catheterization was begun. Two perforations occurred before the septostomy was actually attempted. Blalock-Hanlon procedures were performed in both children. One survived and the other died of complications related to the surgical procedures. A fourth perforation, of the left atrial appendage, was associated with manipulation of the balloon catheter in the left atrium after performance of septostomy. Cardiac arrest occurred but the infant was resuscitated. Thoracotomy was not required, and this infant is still alive. Four children of the II followed for at least six months required a second septostomy. One child sustained a cerebral venous thrombosis. 